\title{
Mineralogical Characteristics of a Micro-Fine and Low Grade Refractory Gold Ore
}

\author{
Yong Chen ${ }^{1 *}$, Yongsheng Song ${ }^{1}$, Wenjuan $\mathrm{Li}^{1}$ and Liulu Cai ${ }^{1}$ \\ ${ }^{1}$ General Research Institute of Nonferrous Metals, National engineering laboratory of biological \\ metallurgy, 100088 Beijing, P.R.China
}

\begin{abstract}
Detailed characterization of a micro-fine, low-grade refractory gold ore from a beneficiation plant in Yunnan Province, China, was investigated. Different analytical techniques, such as videlicet size analysis, scanning electron microscopy, and mineral analysis by a Mineral Liberation Analyser, were used for mineralogical characterization of the ore. The results show that the most valuable metal is gold. Grain size of pyrites and arsenian pyrites, which are main gold carrying minerals, are mostly $1 \sim 30 \mu \mathrm{m}$. The gangue mineral is composed of quartz, mica, dolomite and feldspar, while the content of easy-to-float and clay gangue minerals is up to $33 \%$.
\end{abstract}

\section{Introduction}

With the rapid development of the gold industry, refractory gold ores are becoming increasingly important resources for gold production [1,2]. Among these refractory gold ores, sulfur and micro-grained native gold ores represent a significant challenge, since they are not amenable to gold recovery by direct cyanidation. The gold contained in this type of ore is very finely disseminated and encapsulated in sulfides, which makes it inaccessible to the cyanide solution during direct cyanidation $[3,4]$. Autoclave pressure oxidation (AC POX) of the sulfide ore and subsequent cyanidation is a common technology used to recover the gold in such types of ore. Flotation is often used as a pre-treatment method to refractory gold ore [5].

As the gold-carrier minerals are usually finely disseminated (sometimes under $10 \mu \mathrm{m}$ ) and intimately associated with gangue minerals, a fine grind is necessary to get a high degree of liberation. At the same time, the fine grind usually causes the production of significant quantities of slimes, which comprise easy-to-float gangue minerals such as mica, dolomite, and calcite. These mineral phases are naturally hydrophobic and float readily, competing with the value minerals in the froth phase and resulting in lower concentrate grades.

Many researchers and companies have carried out studies on different kinds of ores using flotation. Marsden and House (2006) examined hydrogen peroxide in the selective flotation of auriferous pyrite with potassium amyl xanthate (PAX). They showed a high selectivity for auriferous pyrite when the $\mathrm{pH}$ exceeded 10 in the slurry, but with a minimal

* Corresponding author: $\underline{\text { cy040311@,163.com }}$ 
increase in recovery. Wang, Wei, Li, and Xie (2006) used the flowsheet of one rough-five cleaners-three scavengers with mixed collectors of butyl xanthate and butyl dithiophosphate on a refractory gold ore from Shuanglong Gold Mine of Shanxin, which contained arsenic and carbon with fine dissemination of gold particles. They achieved concentrate gold grade $36.04 \mathrm{~g} / \mathrm{t}$ and gold recovery of $76.15 \%$. For a low grade gold-bearing sulfide ore from Yunnan Province that contains $1.03 \mathrm{~g} / \mathrm{t} \mathrm{Au}$, the valuable minerals were recovered by flotation using DPS reagent $[6,7,8]$. In micro-fine-grained gold ore containing arsenic and sulfur from the Hubei Province, it may be beneficial to involve measures of stage grindingenhanced dispersion of slime-activated gold-carrier to acquire qualified Au concentrate[9].

Ore from the Zhenyuan gold mine in Yunnan represents a typical refractory gold ore. Under an optical microscope, the maximum size of the gold particles is only $8.5 \mu \mathrm{m}$, while the average particle size is $2-5 \mu \mathrm{m}$. The gold particles are coupled with gangue minerals containing a lot of secondary sericite of mud and clay minerals. The flotation index of the plant is low. In this study, tests were conducted using a Mineral Liberation Analyser (MLA) on the ores. The main objective was to find out the main gold-bearing minerals and dissemination size that influence flotation performance. Attention was paid to the occurrence of main metallic minerals and the mineral liberation degree of pyrite.

\section{Materials and methods}

A composite sample was collected from Zhenyuan gold mine at Ailaoshan district, Yunnan province. Approximately $200 \mathrm{~kg}$ of representative ore samples was crushed to $-2 \mathrm{~mm}$ with a two-stage jaw crusher and one-stage roll crusher. The materials were then well mixed and divided into $1 \mathrm{~kg}$ samples for chemical and mineralogical studies. The sample was analyzed using atomic absorption spectrophotometry (AAS, GGX-9, Beijing, China).

\section{Results and discussions}

\subsection{Chemical component of ore}

The results of multi-element analysis of the sample are shown in Table 1. The result indicates that the most valuable metal in the ore is $\mathrm{Au}$, while the harmful elements mainly are As and C. Table 2 shows the result of chemical phase analysis of $\mathrm{Au}$ in the ore. It demonstrates that sulfide and silicate are the main forms of inclusion gold mineral. The distribution rates of the two forms are $77.94 \%$ and $17.24 \%$ respectively. Single gold and gold trapped by the sulphide accounts for $80.26 \%$, which is the maximum theoretical recovery of $\mathrm{Au}$.

Table 1. Chemical analysis results of the feed ore.

\begin{tabular}{|c|c|c|c|c|c|c|c|}
\hline Elements & $\mathrm{Cu}$ & $\mathrm{Pb}$ & $\mathrm{Zn}$ & $\mathrm{S}$ & $\mathrm{Fe}$ & $\mathrm{Au}(\mathrm{g} / \mathrm{t})$ & $\mathrm{Ag}(\mathrm{g} / \mathrm{t})$ \\
\hline Content/\% & 0.032 & 0.14 & 0.025 & 0.87 & 3.87 & 1.16 & $<5$ \\
\hline Elements & $\mathrm{Ca}$ & $\mathrm{Mg}$ & $\mathrm{SiO}_{2}$ & $\mathrm{Al}$ & $\mathrm{C}$ & $\mathrm{As}$ & $\mathrm{Sb}$ \\
\hline Content/\% & 4.37 & 2.18 & 58.11 & 5.52 & 2.56 & 0.14 & 0.011 \\
\hline
\end{tabular}

Table 2. Chemical phase analysis of $\mathrm{Au}$ in ore.

\begin{tabular}{|c|c|c|c|c|c|c|}
\hline Phase & Single/fissure & Carbonate & Metal oxide & Sulfide & Silicate & Total \\
\hline Mass fraction/\% & 0.018 & 0.02 & 0.009 & 0.913 & 0.20 & 1.16 \\
\hline Distribution rate/\% & 2.32 & 1.72 & 0.78 & 77.94 & 77.94 & 100.00 \\
\hline
\end{tabular}




\subsection{Mineral composition and content of ore}

The mineralogical determination of the feed sample obtained with a Mineral Liberation Analyser (MLA) and back scattered electron imaging (SEM, JSM-6510, Japan, operating at $20 \mathrm{kV}$ ) is shown in Fig. 1. The analysis provided by the MLA is reported elsewhere in detail $[10,11]$.
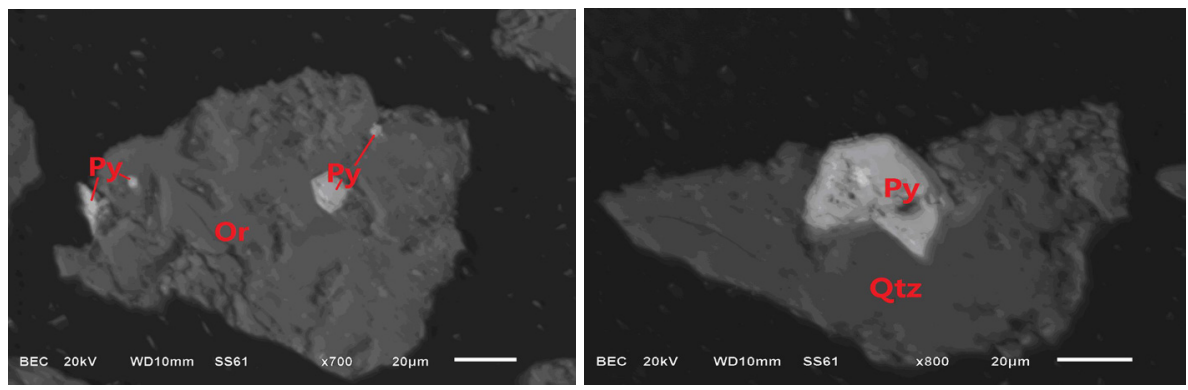

Fig. 1. Selected back scattered electron particle images of the sample illustrating the pyrite (Py) ore mineralogy and textures

From the chemical composition analysis and the MLA results (Fig. 2), it can be seen that the pyrite and quartz were the main sulfide and gangue minerals in the feed ore, respectively. However, the gold-carrier mineral (pyrite) was finely embedded. For the pyrite mineral phase, $61.08 \%$ of the pyrite grains were $<22 \mu \mathrm{m}$. In addition, the pyrite was closely associated with quartz, dolomite, calcite, and muscovite. As a result, the recovery of gold from the ore would be difficult due to the following features:

(1) The grades of gold in the ore were very low, only $1.16 \mathrm{~g} / \mathrm{t}$.

(2) The particle size was very fine, needing fine grinding, which is detrimental to the flotation process.

(3) The content of easy-to-float and clay gangue minerals was up to $33 \%$, so the surface of a number of valuable minerals would be coated by slimes via electrostatic attraction; therefore, their surface hydrophobicity and subsequent flotation would be reduced.

\subsection{Occurrence of main metallic minerals}

Pyrite was the main gold-bearing minerals, some pyrite contained a small amount of chromium (Cr: $0 \sim 4.00 \% \mathrm{wt} \%$ ) and arsenic (As: 0 30.97\% wt\%). The spectrum of pyrite and As-bearing pyrite were shown in Fig. 3. Pyrite accounted for $1.5 \%$ of the total mineral volume, and presented fine-grained mostly disseminated in the gangue, a small amount of vein distribution in the gangue fissure. Pyrite was mostly embedded in quartz, mica and feldspar, or partly wrapped in limonite, chromite, arsenopyrite and porphyrite. The maximum particle size of pyrite in the ore was $1 \mathrm{~mm}$ while the minimum size was only $1 \sim 2$ $\mu \mathrm{m}$, showing two grain size intervals. 


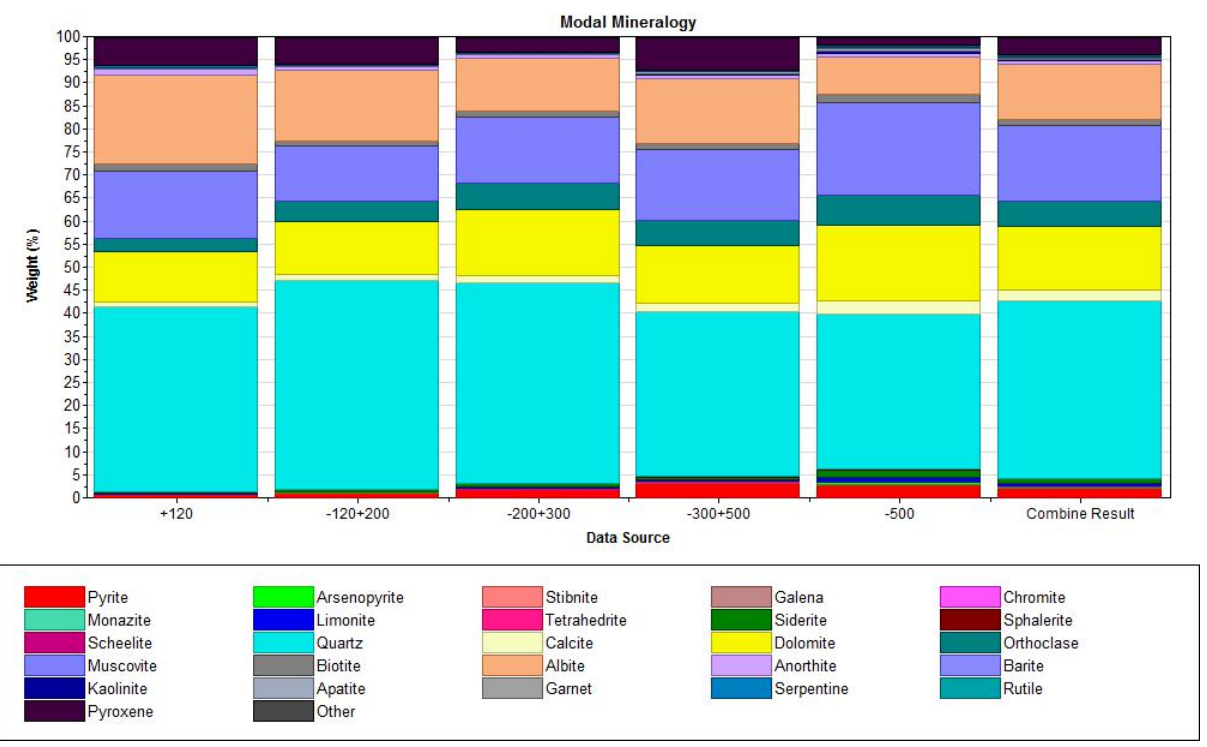

Fig. 2. The mineral composition and content result of the feed ore

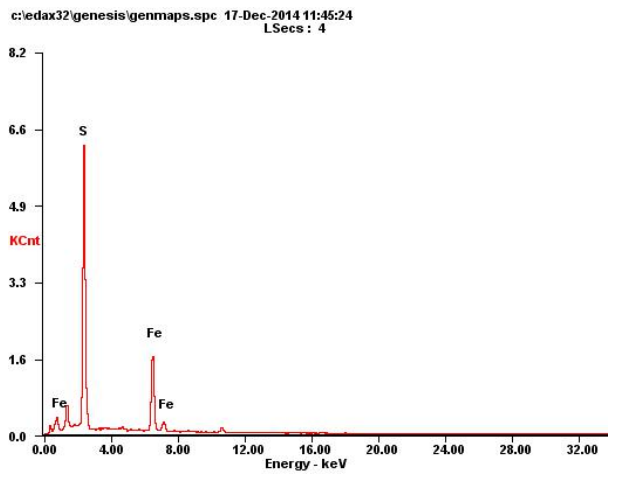

Energy spectrum diagram of pyrite

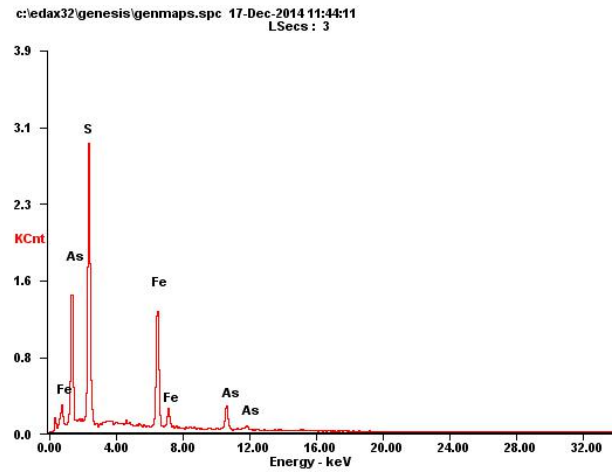

Energy spectrum diagram of arsenopyrite

Fig. 3. The energy spectrum diagram of pyrite and arsenopyrite

\subsection{The main mineral dissociation degree and the relationship}

The relationship of different minerals at a grinding fineness of $70 \%-200$ mesh was shown in table 3. Pyrite free surface was covered for $75.36 \%, 7.42 \%$ contacted with quartz, $5.97 \%$ contacted with muscovite, $3.05 \%$ contacted with dolomite, $3.61 \%$ contacted with albite. These minerals were main gangue minerals associated with pyrite.

Table 3 Interlocking relation between main mineral and other minerals

\begin{tabular}{|c|c|c|c|c|c|c|c|c|c|}
\hline Mineral & pyrite & arsenopyrite & stibnite & galena & tetrahedrite & monazite & chromite & limonite & siderite \\
\hline pyrite & - & 2.57 & 0.20 & 0.00 & 17.21 & 0.00 & 0.86 & 0.71 & 0.03 \\
\hline arsenopyrite & 0.42 & - & 0.00 & 0.00 & 0.00 & 0.02 & 0.13 & 0.58 & 0.01 \\
\hline stibnite & 0.00 & 0.00 & - & 0.00 & 0.00 & 0.00 & 0.00 & 0.00 & 0.00 \\
\hline galena & 0.00 & 0.00 & 0.00 & - & 0.00 & 0.00 & 0.00 & 0.00 & 0.00 \\
\hline chromite & 0.10 & 0.13 & 0.00 & 0.00 & 0.00 & 0.00 & - & 1.93 & 0.42 \\
\hline monazite & 0.00 & 0.00 & 0.00 & 0.00 & 0.00 & - & 0.00 & 0.00 & 0.00 \\
\hline limonite & 0.30 & 3.29 & 0.00 & 0.00 & 0.00 & 0.00 & 9.52 & - & 0.69 \\
\hline tetrahedrite & 0.13 & 0.00 & 0.00 & 0.00 & - & 0.00 & 0.00 & 0.00 & 0.08 \\
\hline
\end{tabular}




\begin{tabular}{|c|c|c|c|c|c|c|c|c|c|}
\hline siderite & 0.03 & 0.03 & 0.00 & 0.00 & 9.61 & 0.00 & 3.69 & 0.99 & \\
\hline sphalerite & 0.00 & 0.00 & 0.00 & 0.00 & 5.68 & 0.00 & 0.00 & 0.00 & 0.00 \\
\hline rutile & 0.02 & 0.00 & 0.00 & 0.00 & 0.00 & 0.00 & 0.00 & 0.04 & 0.00 \\
\hline quartz & 7.42 & 1.76 & 0.04 & 0.51 & 1.19 & 0.92 & 4.14 & 5.63 & 6.95 \\
\hline calcite & 0.40 & 0.00 & 0.00 & 0.00 & 0.00 & 0.00 & 0.19 & 0.06 & 0.05 \\
\hline dolomite & 3.05 & 3.60 & 0.00 & 0.00 & 1.83 & 0.00 & 3.70 & 1.78 & 4.48 \\
\hline orthoclase & 1.21 & 0.14 & 0.00 & 0.00 & 0.95 & 2.19 & 0.60 & 1.67 & 0.97 \\
\hline muscovite & 5.97 & 4.02 & 0.00 & 0.00 & 8.64 & 23.53 & 5.02 & 7.38 & 9.96 \\
\hline biotite & 0.26 & 0.16 & 0.00 & 0.00 & 0.00 & 0.00 & 1.29 & 2.27 & 1.56 \\
\hline albite & 3.61 & 1.12 & 3.57 & 0.00 & 4.04 & 1.69 & 2.29 & 2.72 & 3.24 \\
\hline anorthite & 0.22 & 0.10 & 0.00 & 0.00 & 0.66 & 0.00 & 0.09 & 0.41 & 0.38 \\
\hline barite & 0.02 & 0.00 & 0.00 & 0.00 & 0.00 & 0.00 & 0.00 & 0.00 & 0.00 \\
\hline kaolinite & 0.01 & 0.00 & 0.00 & 0.00 & 0.00 & 0.00 & 0.05 & 0.87 & 0.13 \\
\hline apatite & 0.09 & 0.00 & 0.00 & 0.00 & 0.00 & 0.00 & 0.07 & 0.02 & 0.03 \\
\hline garnet & 0.13 & 0.00 & 0.00 & 0.00 & 0.00 & 4.49 & 0.09 & 0.02 & 0.03 \\
\hline serpentine & 0.02 & 0.00 & 0.00 & 0.00 & 0.00 & 0.00 & 0.36 & 0.07 & 0.16 \\
\hline pyroxene & 1.23 & 0.52 & 0.00 & 0.00 & 0.51 & 0.00 & 0.09 & 2.18 & 0.39 \\
\hline others & 0.00 & 0.00 & 0.00 & 0.00 & 0.00 & 0.00 & 0.00 & 0.00 & 0.13 \\
\hline free surface & 75.36 & 82.57 & 96.18 & 99.49 & 49.67 & 67.10 & 67.83 & 70.66 & 70.29 \\
\hline Total & 100.00 & 100.00 & 100.00 & 100.00 & 100.00 & 100.00 & 100.00 & 100.00 & 100.00 \\
\hline
\end{tabular}

\section{Conclusions}

Mineralogical analysis of the feed using MLA indicated that pyrite was the main gold host mineral in the ore. Quartz, muscovite, and dolomite were identified as the principal gangue minerals. The total content of easy-to-float and clay gangue minerals was up to $33 \%$. Pyrite was the main gold carrying mineral but finely embedded, with almost $61.08 \%$ of the pyrite particles being $<22 \mu \mathrm{m}$. the recovery of gold from the ore would be difficult.

The authors are grateful for the financial support from National Natural Science Foundation of China (No.51504031) and China Gold group for this work. We would like to express our sincere appreciation to the anonymous reviewers for generous advice and help for language modification

\section{References}

1. O' Connor C.T., Dunne R.C., The flotation of gold bearing ores-a review. Min. Eng., 7, 839 (1994)

2. Agorhom, E. A., Skinner, W., \& Zanin, M. Upgrading of low-grade gold ore samples for improved particle characterisation using Micro-CT and SEM/EDX. Advanced Powder Technology, 23, 498 (2012)

3. Allan, G.C., \& Woodcock, J.T. A review of the flotation of native gold and electrum. Minerals Engineering, 14, 931 (2001)

4. Bulatovic, S.M. Flotation behaviour of gold during processing of porphyry coppergold ores and refractory gold-bearing sulphides. Minerals Engineering, 10, 895.(1997)

5. Monte, M.B.M., Lins, F.F., Oliveira, J.F., Selective flotation of gold from pyrite under oxidizing conditions. Int. J. Miner. Process. 51, 255(1997)

6. Bradshaw, D.J., Harris, P.J., \& O' Connor, C.T. Synergistic interactions between reagents in sulphide flotation. J. S. Afr. Inst. Min. Metall., 98, 187 (1998)

7. Wang, X.F., Wei Y.R., Li J.B., Xie J.H., Flotation of refractory gold ore containing arsenic and carbon with fine gold dissemination from shuanglong gold mine in Shanxi of china. Nonferrous Metals. 6, 63(2006) 
8. Jue, S.J., Wang, H.F., \& Zhao, F. Beneficiation experimental investigation on a low grade gold-bearing sulfide ore. Yunan Metallurgy, 1, 18 (2012)

9. Lin F., Li X.Y., Xiao Y.Y., Li Y., Study on Flotation Test of Microfine-grained Gold Ore Containing Arsenic and Sulfur. Resources Environment\& Engineering, 4, 192 (2009)

10. Gu, Y. Automated scanning electron microscope based mineral liberation analysis. Journal of Minerals and Materials Characterization and Engineering, 5, 2(2003)

11. Fandrich, R., Gu, Y., Burrows, D., \& Moeller, K. Modern SEM-based mineral liberation analysis. International Journal of Mineral Processing, 84, 310(2007) 